launch a full-blooded opposition to the White Paper through the media.

'Caer Beris'

M. R. MORTON

Pool Head, Bodenham

Herefordshire HRI $3 H P$

\section{Alternative mental health care services for black people}

DeAr SIRS

I was most impressed by the descriptions of alternative mental health care services for black people by Francis et al in the Psychiatric Bulletin (September $1989,13,482-485)$. When the proposals of Working for Patients are implemented, I wonder if it will become possible for these groups to bill the relevant health authorities or budget-holding GPs for their work. If so, the local NHS facilities would presumably take a corresponding cut in revenue. This would certainly provide a stimulus for the NHS facilities to look at their cross cultural acceptability.

GyLES R. GlOVER

Charing Cross and Westminster Medical School

Department of Community Medicine

London SWIP 2AR

\section{Appropriate terminology in cross- cultural studies}

DEAR SIRS

I found disturbing the use, without definition, of terms such as "black" and "Afro-Caribbean" by Fernando (Psychiatric Bulletin, May 1989, 13, 250-251) and Harrison (Psychiatric Bulletin, May 1989, 13, 251). While this is, of course, a very common tendency in reports on "cross-cultural" studies, I suspect that the use of such terms has very little scientific value and serves mainly to evoke stereotypes. It is important that when studying or writing about various cultural groups, as much trouble be taken to describe the population involved as is taken to define any aspect of psychopathology being investigated. For example, it is usually more relevant to know the length of time migrants have been in the country, their age, sex, marital status, social class, command of the language and degree of acculturation than the amount of skin pigmentation present - and incidentally, the precise amount of pigmentation has not been without importance in interpersonal situations over the centuries.

I do appreciate that Drs Fernando and Harrison may well be using these terms as a form of shorthand unfortunately, this is a practice fraught with dangers, and certainly likely to lead to bad science.

What, then, is the alternative? I suggest it is to define very clearly at the outset what one means by such terms, and perhaps to seek the advice of anthropologists as to the most appropriate and informative terminology for a particular purpose.

University Department of Psychiatry

I. PILowsky

Royal Adelaide Hospital

Adelaide, South Australia 5001

\section{Mental Health (Scotland) Act 1984}

\section{DeAR SIRS}

Perusing the Gaskell Publications of the Royal College of Psychiatrists Book List I discovered a publication on a hereto unknown piece of legislation "The Mental Health Act 1983 (Scotland)".

The name of the Scottish legislation is the "Mental Health (Scotland) Act 1984". There was also a Mental Health (Amendment) (Scotland) Act 1983.

By delaying a year Scotland produced a more sensible Act.

Rampton Hospital

A. P. W. Shubsachs 